\title{
Germinação e formação de mudas de coqueiro irrigadas com águas salinas ${ }^{1}$
}

Francisco J. L. Marinho ${ }^{2}$, Hans R. Gheyi ${ }^{3}$ \& Pedro D. Fernandes ${ }^{3}$

\author{
1 Trabalho financiado pelo $\mathrm{CNPq}$ \\ 2 EAAC/UEPB. Bairro Vila Florestal, CEP 58.117-000 Lagoa Seca, PB. Fone (83) 3331-3845. E-mail: chicohare@bol.com.br \\ ${ }^{3}$ DEAg/CCT/UFCG, CP 10.078, CEP 58109-970, Campina Grande, PB. Fone (83) 3310-1185. E-mail: hans@deag.ufcg.edu.br, \\ pdantas@deag.ufcg.edu.br
}

\author{
Protocolo $14-27 / 8 / 2004$ - Aprovado em 5/4/2005
}

\begin{abstract}
Resumo: O cultivo de coqueiro vem crescendo no Nordeste, com aumento de produtividade, quando irrigado. Sendo comuns na região águas salinas e se considerando a carência de dados de pesquisa de salinidade em coqueiro anão-verde (Cocos nucifera L.), objetivou-se, através deste trabalho, avaliar os efeitos da irrigação com águas salinas (CEa = 2,2, 5, 10, 15 e $20 \mathrm{dS} \mathrm{m}^{-1}$ ) sobre a germinação e o crescimento inicial de plântulas, até 120 dias após semeadura (fase I), estendendo-se a avaliação, posteriormente, após repicagem para o viveiro, quando passaram a ser irrigadas com água de $\mathrm{CEa}=2,2 \mathrm{dS} \mathrm{m}^{-1}$, durante 120 dias (fase II), estudando-se o efeito residual dos níveis de salinidade aplicados na fase I. Em ambos os experimentos, o delineamento foi inteiramente casualizado, com quatro repetições. As águas salinas foram preparadas com adição de $\mathrm{NaCl}$ comercial. Na primeira fase, o incremento da CEa não influenciou significativamente a germinação que variou de 80 a 97,5\%, porém afetou a velocidade de germinação e o crescimento das plântulas; na fase de sementeira, a salinidade afetou a fitomassa total a partir de $5,4 \mathrm{dS} \mathrm{m}^{-1}$; o sistema radicular foi a variável mais afetada pela salinidade. Na fase II, as plantas oriundas de germinação sob condições de alta salinidade, após passarem a ser irrigadas com água de 2,2 dS m-1, cresceram no mesmo ritmo daquelas germinadas sem estresse salino.
\end{abstract}

Palavras-chave: Cocos nucifera, estresse salino, fitomassa

\section{Germination and seedling formation of coconut irrigated with saline waters}

\begin{abstract}
The coconut cultivation is growing in the Northeast Brazil with increase in productivity under irrigated conditions. Saline waters are commonly found in this region and considering the lack of data related to salinity on dwarf-green coconut (Cocos nucifera L.), this work had the objective of evaluating the effects of the irrigation with saline waters $(E C w=2.2,5,10,15$ and $20 \mathrm{dS} \mathrm{m}^{-1}$ ) on the germination and the initial growth of seedlings until 120 days after sowing (phase I), extending the evaluation, later, after transplanting in the nursery, when seedlings were irrigated with water of ECw $=2.2 \mathrm{dS} \mathrm{m}^{-1}$, for another 120 days (phase II), studying the residual effect of the applied salinity levels in the phase I. In both the experiments a completely randomized design was used with four replications. The saline waters were prepared with the addition of commercial $\mathrm{NaCl}$. In the first phase, the increment of $\mathrm{ECW}$ did not influence the germination significantly, which varied from 80 to $97.5 \%$, however, it affected the germination speed and the growth of the seedlings; in the germination phase the salinity affected the total phytomass starting from $5.4 \mathrm{dS} \mathrm{m}^{-1}$; the root system was the most affected variable by the water salinity. In the phase II, the plants germinated under conditions of high salinity when irrigated with water of $2.2 \mathrm{dS} \mathrm{m}^{-1}$ maintained the rhythm of growth similar to those germinated without saline stress.
\end{abstract}

Key words: Cocos nucifera, salinity stress, phytomass 


\section{INTRODUÇÃO}

O coqueiro é uma importante cultura de regiões intertropicais, por gerar um sistema auto-sustentável de exploração, ser significativa fonte de divisas e fornecer proteínas e calorias para a população, a exemplo do que ocorre em vários países do continente asiático (Cuenca, 1998).

Na região Nordeste, que contribui com $72,2 \%$ da produção nacional (IBGE, 2000), a cultura de coco tem grande expressividade social e econômica, principalmente para as populações litorâneas, ressaltando-se que vem ocorrendo, nos últimos anos, incremento considerável da área plantada no interior da região.

Segundo Fontes et al. (1998), é imprescindível a irrigação de sementes de coqueiro no germinadouro para acelerar a velocidade de germinação; a necessidade de água nessa fase é de 6 a $7 \mathrm{~mm} \mathrm{~d}^{-1}$ ( 6 a $\left.7 \mathrm{~L} \mathrm{~m}^{-2}\right)$, recomendando-se irrigações em dois turnos, ou seja, no início da manhã e no final da tarde.

Em todo o mundo, a pressão por águas de boa qualidade e a expansão das áreas agrícolas têm gerado a necessidade do uso de águas de qualidade marginal na irrigação (Noaman \& El-Haddad, 2000; Zeng et al., 2001). Neste contexto, é grande o potencial de uso de águas salinas na agricultura, contanto que sejam adotadas práticas adequadas de manejo da irrigação (Aldesuquy \& Ibrahim, 2001; Tester \& Davenport, 2003).

A salinidade, tanto de solos como de águas, é uma das principais causas de queda do rendimento das plantas (Tester \& Davenport, 2003), devido aos efeitos de natureza osmótica, tóxica e/ou nutricional, afetando processos metabólicos vitais, como fotofosforilação, cadeia respiratória, assimilação do nitrogênio e metabolismo das proteínas (Munns, 2002). Entretanto, os efeitos dependem de muitos outros fatores, como espécie, cultivar, estádio fenológico, características dos sais, intensidade e duração do estresse salino, manejo cultural e da irrigação e condições edafoclimáticas (Alian et al., 2000; Tester \& Davenport, 2003).

Várias espécies podem até mesmo ser favorecidas quando expostas a concentrações salinas de $\mathrm{NaCl}$ (Tester \& Davenport, 2003). Determinadas plantas são beneficiadas pela salinidade durante a germinação, o que lhes confere maior capacidade de adaptação à salinidade durante o restante do ciclo (Manchanda \& Bhandhari, 1976; Viana et al., 2004).

Com relação ao coqueiro, são encontrados dados de pesquisa envolvendo aspectos de salinidade (Pomier \& Brunin, 1974; Yusuf \& Varadan, 1993; Ferreira Neto, 2001; Silva Jr. et al., 2002); entretanto, a maioria desses trabalhos foi desenvolvida utilizando-se da variedade Gigante e em condições edafoclimáticas e estádio fenológico diferentes das do presente estudo.

Ante o exposto, procurou-se estudar o aproveitamento de água salina, analisando-se os efeitos de diferentes níveis de salinidade da água de irrigação sobre a cultura do coqueiro cv. Anão-verde, durante a germinação e seus efeitos sobre a fase inicial de viveiro, visando a criar oportunidade de trabalho e fonte alternativa de renda em regiões com escassez de água de baixa salinidade.

\section{MATERIAL E MÉTODOS}

O experimento foi conduzido no Viveiro Florestal da Prefeitura Municipal de Campina Grande, PB, em duas fases: na primeira foram estudados, entre os meses de novembro/ 1999 e março/2000, os efeitos de cinco níveis de salinidade da água sobre a germinação e o crescimento de plântulas de coqueiro (Cocos nucifera L.), até 120 dias após a semeadura (DAS); na fase II (março a julho de 2000) avaliou-se, em condições de viveiro, o efeito residual dos tratamentos aplicados na primeira fase sobre a sobrevivência e o crescimento das mudas, por 120 dias, irrigadas com água de $2,2 \mathrm{dS} \mathrm{m}^{-1} \mathrm{de}$ condutividade elétrica.

\section{Fase I. Germinação e crescimento inicial de plântulas}

Os tratamentos constaram de cinco níveis de salinidade na água de irrigação, expressos pela condutividade elétrica [CEa: $\mathrm{T}_{1}=2,2$ (controle); $\left.\mathrm{T}_{2}=5 ; \mathrm{T}_{3}=10 ; \mathrm{T}_{4}=15 \mathrm{e} \mathrm{T}_{5}=20 \mathrm{dS} \mathrm{m}^{-1}\right] . \mathrm{O}$ delineamento experimental adotado foi o inteiramente casualizado com quatro repetições e parcelas com 10 sementes.

As águas salinas foram preparadas adicionando-se quantidades de $\mathrm{NaCl}$ comercial, isento de iodo, à água proveniente de poço tubular $\left(\mathrm{CE}=2,2 \mathrm{dS} \mathrm{m}^{-1}\right)$ e armazenadas em recipientes de $\mathrm{PVC}$ com capacidade de $200 \mathrm{~L}$.

Construíram-se, na área experimental, 20 canteiros em alvenaria, com área de $0,5 \mathrm{~m}^{2}(0,5 \times 1,0 \mathrm{~m} \mathrm{e} 0,25 \mathrm{~m}$ de altura $)$, protegidos sob tela sombrite $(50 \%)$ e piso com declividade de $5 \%$, para facilitar a drenagem. Os canteiros foram preenchidos com material de solo arenoso contendo, respectivamente, 802 , $41 \mathrm{e} 57 \mathrm{~g} \mathrm{~kg}^{-1}$ de areia, silte e argila.

As sementes de coqueiro 'Anão Precoce', colhidas em completo estado de maturação (12 meses), foram preparadas retirando-se, através de chanfragem, parte da casca do coco de maior protuberância, próximo à cicatriz do ponto de inserção do pedúnculo; colocaram-se, em cada germinadouro, 10 sementes, em posição vertical, com a extremidade da cicatriz para cima, cobertas com substrato, até aproximadamente $2 / 3$ das mesmas (Fontes et al., 1998).

As irrigações foram realizadas com águas correspondentes aos tratamentos, no período da manhã, ao meio dia e no final da tarde, através de uma lâmina equivalente a $5 \mathrm{~mm} \mathrm{~d}^{-1}$; no cálculo da lâmina levou-se em consideração a ocorrência de pluviosidade, fazendo-se as devidas compensações.

Diariamente e durante 120 dias, fez-se a contagem do número de sementes germinadas adotando-se, como critério, o aparecimento do epicótilo; com base nesses dados calculouse o tempo médio para germinação (TG) e a percentagem de germinação (PG).

Aos 120 dias após semeadura, o crescimento das plântulas foi avaliado pelo diâmetro do coleto (DC) e comprimento das plântulas (CP); na determinação de CP considerou-se a distância entre o colo da plântula e a extremidade da maior folha esticada verticalmente. Em 4 plântulas de cada canteiro foram determinadas, através de secagem em estufa $\left(65^{\circ} \mathrm{C}\right)$ até peso constante, a fitomassa da raiz (FR) e da parte aérea (FPA), calculando-se, a partir desses dados, a fitomassa total (FT) e a relação raiz/parte aérea (R/PA). 


\section{Fase II. Crescimento de mudas em viveiro}

Nesta fase, avaliou-se o efeito residual dos tratamentos salinos aplicados na germinação das sementes $\left(\mathrm{T}_{1}\right.$ a $\left.\mathrm{T}_{5}\right)$ sobre as plântulas na fase de viveiro, quando todas passaram a ser irrigadas com água de $2,2 \mathrm{dS} \mathrm{m}^{-1}$. O delineamento experimental adotado também foi o inteiramente casualizado, com quatro repetições e 4 mudas por repetição.

As plântulas com altura média de 37,7, 33,6, 23,2, 22,3 e 10,8 $\mathrm{cm}$, respectivamente correspondentes aos 5 tratamentos, foram repicadas para sacos de polietileno preto com dimensões de $0,65 \mathrm{~m}$ de altura e $0,55 \mathrm{~m}$ de diâmetro, cobertas até a altura do coleto com substrato, composto de uma mistura de material de solo de textura franca, areia lavada e húmus de minhoca, na proporção 1:1:1; os recipientes ficaram dispostos em canteiros de alvenaria, construídos de forma idêntica aos descritos na fase anterior. As irrigações foram realizadas em 2 turnos (início da manhã e no final da tarde) utilizando-se de lâmina equivalente a $7 \mathrm{~mm} \mathrm{~d}^{-1}$ (3,5 L por canteiro).

As adubações, de acordo com recomendações de Fontes et al. (1998), iniciaram-se 30 dias após o transplantio do germinadouro para o viveiro, sendo aplicadas em cobertura, até o $3^{\circ}$ mês, parcelas mensais de $10 \mathrm{~g}$ de superfosfato simples, $5 \mathrm{~g}$ de nitrato de potássio, 3,3 g de uréia e 1,6 $\mathrm{g}$ de cloreto de potássio por planta.

Mensalmente, anotou-se o número de mudas sobreviventes e o comprimento das mudas (CM), calculando-se, também, o incremento percentual em relação à fase anterior e a taxa de crescimento diário (TCD), com base no comprimento das plantas no momento da repicagem para o viveiro e aos 120 dias após repicagem (DAR).

Aos 120 DAR, foram utilizadas duas plantas por parcela, para obtenção de fitomassa da raiz (FR) e da parte aérea (FPA), calculando-se, a partir desses dados, a fitomassa total (FT) e a relação raiz/parte aérea $(\mathrm{R} / \mathrm{PA})$.

Os dados obtidos em ambas as fases foram submetidos à análise de variância simples e ao teste "F", segundo procedimentos estatísticos (Ferreira, 2000). Foram realizadas, também, análises de regressão polinomial, obtendo-se equações de regressão, utilizando-se de modelos linear, quadrático e "linear response plateau"-LRP (Braga, 1983).

\section{RESULTADOS E DISCUSSÃO}

\section{Fase I. Germinação e crescimento inicial de plântulas}

$\mathrm{O}$ percentual de germinação (PG) não foi afetado pelas concentrações salinas da água de irrigação, com valores médios de 97,5 e $80,0 \%$ das sementes germinadas em $\mathrm{T}_{1}$ e $\mathrm{T}_{5}(2,2$ e 20 $\mathrm{dS} \mathrm{m}^{-1}$ ), respectivamente (Tabela 1); estes resultados são elevados, visto que Fontes \& Leal (1994) obtiveram, em condições normais de germinação de coco, sem indução de estresse abiótico, índices variando entre 68,8 e 74,7\%.

Nos estudos de regressão detectou-se aumento linear $(\mathrm{p}<$ $0,01)$ do tempo médio para germinação das sementes (TG); segundo a equação obtida (Tabela 1), ocorreu acréscimo de $1 \%$ por aumento unitário de CEa em relação ao controle $\left(\mathrm{T}_{1}\right)$, ou seja, ocorreu aumento no tempo necessário para as sementes germinarem de 0,63 dia por incremento unitário da $\mathrm{CEa}$, de modo que as sementes irrigadas com água de maior salinidade $\left(20 \mathrm{dS} \mathrm{m}^{-1}\right)$
Tabela 1. Resumo de ANAVA para percentual de germinação (PG) e tempo médio para germinação (TG) sob diferentes níveis de salinidade da água de irrigação $(\mathrm{CEa})$

\begin{tabular}{|c|c|c|}
\hline \multirow{2}{*}{ Fonte de variação } & $\mathrm{PG}$ & TG \\
\hline & \multicolumn{2}{|c|}{ Quadrado médio } \\
\hline Salinidade & $224,7^{\mathrm{ns}}$ & $91,10 * *$ \\
\hline Regressão Linear & $655,3^{\mathrm{ns}}$ & $253,90 * *$ \\
\hline Desv. Reg. & $118,7^{\mathrm{ns}}$ & $42,08^{\mathrm{ns}}$ \\
\hline Resíduo & 152,8 & 27,47 \\
\hline \multirow[t]{2}{*}{ CV (\%) } & 13,6 & 7,71 \\
\hline & \multicolumn{2}{|c|}{ Média } \\
\hline $\mathrm{CEa}\left(\mathrm{dS} \mathrm{m}^{-1}\right)$ & $(\%)$ & (dias) \\
\hline 2,2 & 97,50 & 62,80 \\
\hline 5 & 97,50 & 63,18 \\
\hline 10 & 86,87 & 71,33 \\
\hline 15 & 92,50 & 68,92 \\
\hline 20 & 80,00 & 74,61 \\
\hline
\end{tabular}

demoraram, em média, 11,2 dias a mais para germinar que as do tratamento $\mathrm{T}_{1}\left(2,2 \mathrm{dS} \mathrm{m}^{-1}\right)$.

Normalmente a redução do potencial osmótico devido à salinidade, provoca mudanças na germinação. Uma das alterações ocorridas é o acréscimo do tempo necessário para germinação das sementes. O retardamento da emissão do broto germinativo pode ser atribuído à desaceleração na transferência das reservas do endosperma para o eixo embrionário, afetando a salinidade as reações enzimáticas envolvidas nesse processo (Ghoulam \& Fares, 2001).

Foi significativo $(\mathrm{p}<0,01)$ o efeito da salinidade sobre a formação de fitomassa de raízes (FR), parte aérea (FPA) e total (FT), aos 120 DAS (Tabela 2); esse efeito é melhor visualizado através da representação gráfica contida na Figura 1.

Apesar da regressão linear significativa, o modelo mais adequado para se avaliar o efeito da salinidade da água de irrigação sobre essas variáveis é o 'linear response plateau' LRP (Braga, 1983), aplicável ao presente caso, por ser possível a identificação do nível de $\mathrm{CEa}$, a partir do qual houve decréscimo dos valores obtidos (Figura 1). Verifica-se que $\mathrm{T}_{1} \mathrm{e}$ $\mathrm{T}_{2}\left(2,2\right.$ e $\left.5 \mathrm{dS} \mathrm{m}^{-1}\right)$ formam um platô, havendo redução linear de FR, FPA e FT a partir de 4,62, 4,97 e 5,06 dS m m $^{-1}$, com decremento respectivo de 7,0, 5,1 e 5,5\%, por incremento unitário de $\mathrm{CEa}$ em relação ao início do declínio. Pelos percentuais, nota-se que o sistema radicular (Figura 1A) foi, portanto, a parte da plântula mais afetada pela salinidade. A redução da fitomassa das plântulas nos tratamentos mais salinos ocorreu, provavelmente, devido ao aumento da pressão osmótica do substrato provocado pelo estresse salino e conseqüente diminuição da absorção de água pelas plântulas, fato comumente reportado na literatura (Katerji et al., 2003; Bie et al., 2004).

Com relação à fitomassa total (Figura $1 \mathrm{C}$ ), o estresse salino provocou reduções de 38,1, 57,9 e 69,8\% nos tratamentos $\mathrm{T}_{3}$, $\mathrm{T}_{4}$ e $\mathrm{T}_{5}$, respectivamente, em relação ao controle $\left(\mathrm{T}_{1}\right)$. E sobre a relação raiz/parte aérea (Figura 1D), a salinidade interferiu, significativamente, com valor de R/PA no tratamento $\mathrm{T}_{5}$ de $1,81 \%$ (Figura 1), enquanto no tratamento $T_{1}$ foi de $20,09 \%$; verifica-se, no modelo LRP, redução linear a partir de CEa de $5,46 \mathrm{dS} \mathrm{m}^{-1}$, com decréscimo de $6,0 \%$ por incremento unitário 
A.

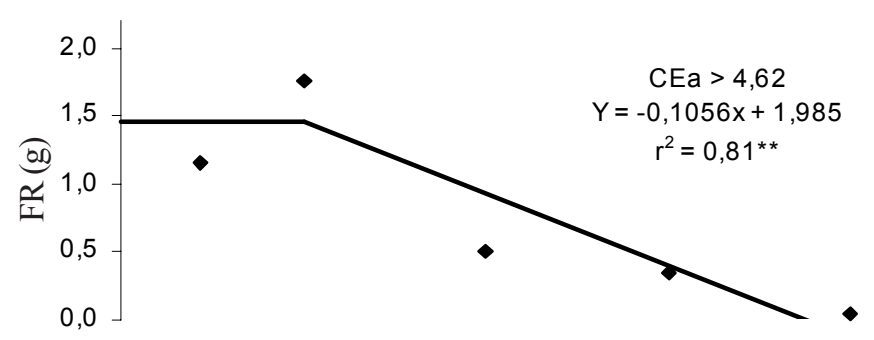

B.

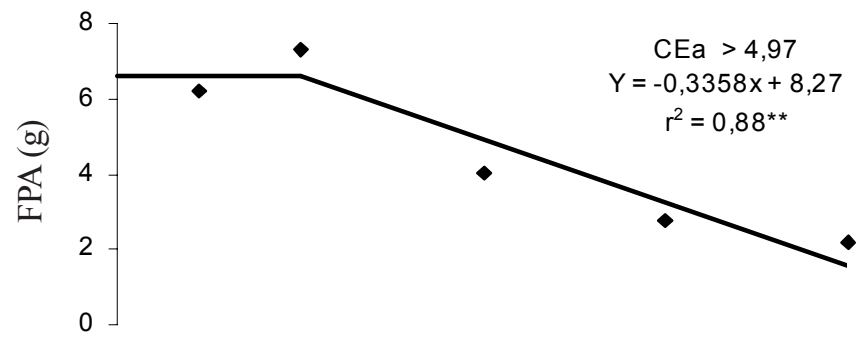

C.
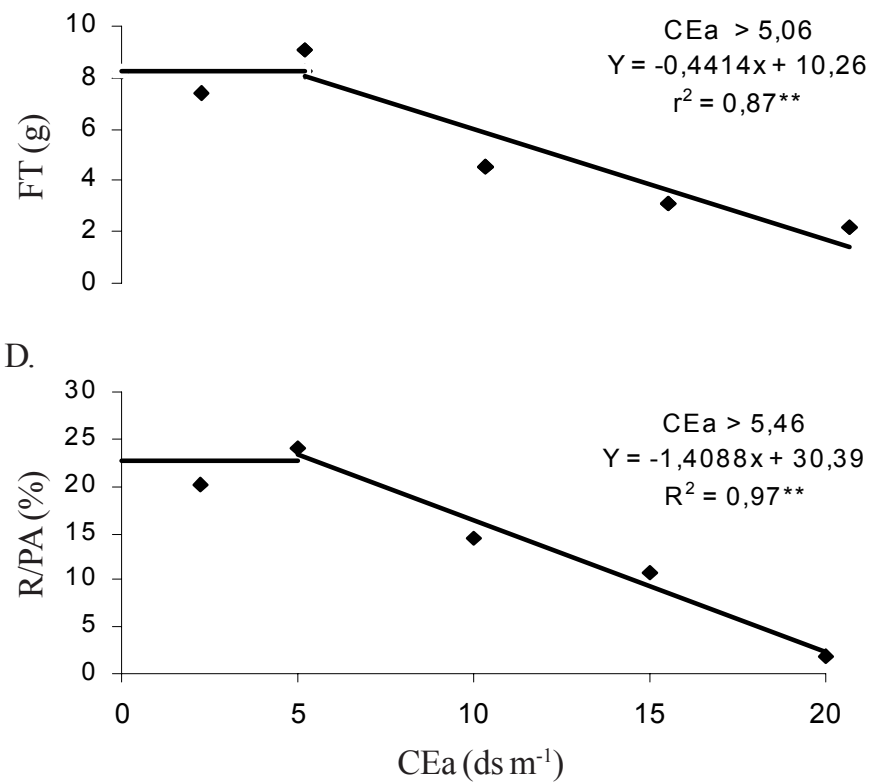

Figura 1. Fitomassa de raízes (FR - A), parte aérea (FPA - B) e total (FT - C) e relação raiz/parte aérea (R/PA - D), aos 120 dias após semeio, em função da salinidade da água de irrigação (CEa)

da CEa em relação ao início do declínio. Da mesma forma como discutido para as variáveis de fitomassa, analisadas isoladamente, o decremento da relação R/PA, com o aumento da condutividade elétrica da água de irrigação, é mais um indicativo de ser o sistema radicular a parte da plântula de coco mais afetada pela salinidade. Na literatura são encontradas referências de ser mais afetada a parte aérea (Rodrigues et al., 2002; Alshammary et al., 2004; Bie et al., 2004), sendo interpretada como adaptação da planta ao estresse salino, reduzindo a superfície transpiratória, uma forma de economizar água, já que aumenta a dificuldade de absorção hídrica, por se tornar mais negativo o potencial osmótico da solução do solo.

A redução mais acentuada do sistema radicular nas plântulas de coco, em níveis elevados de salinidade, pode estar
Tabela 2: Resumo de ANAVA para fitomassa de raízes (FR), parte aérea (FPA) e total (FT) e relação raiz/ parte aérea (R/ PA) das plântulas em condições de sementeira, em função de diferentes níveis de salinidade da água de irrigação (CEa), aos 120 dias após semeadura

\begin{tabular}{lcccc}
\hline \multirow{2}{*}{ Fonte de variação } & FR & FPA & FT & R/PA \\
\cline { 2 - 5 } & \multicolumn{4}{c}{ Quadrado Médio } \\
\hline Salinidade & $1,89^{* *}$ & $19,63^{* *}$ & $3,50^{* *}$ & $297,80^{*}$ \\
Regr. Pol. Linear & $5,65^{* *}$ & $67,53^{* *}$ & $112,26^{* *}$ & $1064,50^{* *}$ \\
LRP & $5,60^{* *}$ & $56,38^{* *}$ & $97,61^{* *}$ & $977,60^{* *}$ \\
Desv. Reg. & $7,34^{* *}$ & $5,34^{\mathrm{ns}}$ & $10,90^{\mathrm{ns}}$ & $70,31^{\mathrm{ns}}$ \\
Resíduo & 0,13 & 2,94 & 3,46 & 43,54 \\
Resíduo (LRP) & 0,15 & 2,40 & 2,86 & 45,80 \\
CV (\%) & 17,36 & 18,10 & 15,37 & 16,32 \\
\hline
\end{tabular}

LRP - Linear Response Plateau (**); Significativo a 0,$01 ;\left({ }^{\text {ns }}\right)$ Não significativo

ligada a mecanismos fisiológicos do coqueiro que estimulam mais o crescimento da parte aérea, decorrente do tipo de semente rica em substâncias de reserva; outro fator a ser, também, considerado, é o tipo de folha do coqueiro, com tecidos do limbo ricos em esclerênquima, epiderme espessa e de textura grossa, tendo inclusive estômatos localizados apenas na face inferior (FAO, 1984), o que, naturalmente, resulta em menor perda de água por transpiração. Constata-se que, mesmo no tratamento com mais baixa condutividade elétrica $\left(\mathrm{T}_{1}\right)$, a FPA foi mais de cinco vezes superior à das raízes e, com o incremento da salinidade, aumentou ainda mais a proporção da parte aérea em relação ao sistema radicular. Na literatura são encontrados resultados semelhantes em abacaxizeiro (Marinho et al., 1998), alho (Amorim et al., 2002) e em aceroleira (Gurgel et al., 2003), cujos autores constataram ser a parte aérea dessas plantas menos sensível à salinidade que as raízes.

\section{Fase II. Crescimento de mudas no viveiro}

A sobrevivência de todas as plântulas germinadas continuou na fase de viveiro, não se observando perdas de mudas, denotando-se, portanto, que a utilização de águas salinas na fase de sementeira não exerceu efeito residual sobre a sobrevivência das plantas na fase seguinte, quando passaram a ser irrigadas com água de $2,2 \mathrm{dS} \mathrm{m}^{-1}$. Infere-se que, durante a germinação, provavelmente o coqueiro possua mecanismos fisiológicos que permitem a adaptação a ambientes salinos sem perdas significativas na resistência, decorrente dos elevados níveis de água e nutrientes contidos no endosperma (FAO, 1984).

A variável comprimento de mudas (CM) foi afetada, significativamente $(p<0,01)$, pelos tratamentos (Tabela 3 ), em todas as avaliações realizadas entre 30 e 120 dias após repicagem (DAR). Os efeitos da salinidade da água de irrigação, aplicada durante a fase de sementeira, foram sendo paulatinamente superados na fase de viveiro, quando as plantas passaram a ser irrigadas com água de $2,2 \mathrm{dS} \mathrm{m}^{-1}$, pois aos $30,60,90$ e 120 DAR o incremento unitário da $\mathrm{CEa}$ resultou em decréscimo no comprimento das mudas, respectivamente de 3,82, 2,82, 2,11 e $1,35 \%$ (comparado a $\mathrm{T}_{1}$ ). Aos $30 \mathrm{DAR}$ o comprimento médio das mudas em $\mathrm{T}_{2}, \mathrm{~T}_{3}, \mathrm{~T}_{4}$ e $\mathrm{T}_{5}$ correspondia, respectivamente, a $88,1,72,6,68,0$ e $46,0 \%$ dos valores de $T_{1}$, enquanto aos 120 
DAR, estes valores foram $96,2,89,4,82,7$ e $75,9 \%$, denotandose que as plantas se recuperaram do estresse salino com o decorrer do tempo, enquanto estavam no viveiro. Este fato pode ser mais bem observado pelos dados de incremento percentual entre os intervalos estudados, cujos valores estão entre parênteses, ao lado das médias (Tabela 3); até aos 90 DAR, o incremento percentual foi, em geral, crescente com o aumento da salinidade, registrando-se os maiores valores em $\mathrm{T}_{5}$; entretanto, de 90 para 120 DAR praticamente não houve diferenças no percentual de aumento do comprimento das mudas, entre tratamentos, comprovando a sua recuperação paulatina. Fato semelhante foi registrado em trigo e cevada por Manchanda \& Bhandhari (1976) e em alface por Viana et al. (2004), recuperando-se as plantas do estresse salino, em fases posteriores de seu ciclo. Na literatura esse fenômeno é denominado 'hardening' ou aclimatação, ocorrendo alterações bioquímicas e fisiológicas no metabolismo para se adaptar ao estresse, consistindo, em geral, de produção de prolina e glicina betaína, dentre outros compostos orgânicos (Bray et al., 2000; Hasegawa et al, 2000).

Não se constatou diferença significativa na taxa de crescimento diário (TCD) em comprimento das mudas, entre a fase de repicagem e aos 120 DAR (Tabela 3), mais uma constatação da recuperação na fase de viveiro dos efeitos salinos a que estavam submetidas as plântulas na fase de germinação e crescimento inicial; portanto, os efeitos negativos da salinidade na sementeira não influenciaram negativamente o crescimento das mudas em comprimento quando elas passaram a ser irrigadas com água de baixa salinidade, porém, provocaram aumento do tempo necessário para que as mesmas alcançassem, no viveiro, tamanho adequado para plantio no campo.

O resumo da análise de variância e as médias de FT, com a respectiva equação de regressão, e da relação R/PA, ao final do período de viveiro, estão na Tabela 4. Constatou-se efeito residual da irrigação com águas salinas, durante a fase de germinação na sementeira, reduzindo significativamente a FT das mudas no viveiro; portanto, o efeito residual da salinidade sobre as mudas ainda era notado, mesmo após 120 dias de irrigação com águas de baixa salinidade $\left(2,2 \mathrm{dS} \mathrm{m}^{-1}\right)$. De acordo com a equação de regressão, ao final da fase de viveiro foi de $3,2 \%$ o decréscimo de FT em relação a $T_{1}$, por incremento unitário da CEa utilizada na fase de sementeira.

Analisando-se as equações de regressão, obtidas para FT em ambas as fases, constata-se ter havido recuperação da fitomassa das plantas na fase de viveiro, pois enquanto o decréscimo de FT entre os níveis de CEa de 10 e $20 \mathrm{dS} \mathrm{m}^{-1}$ chegou a $75 \%$ na primeira fase, na segunda a queda foi de apenas $43 \%$; além disso, nota-se que ao final da fase de viveiro $\mathrm{o}$ incremento percentual da FT, em relação à fase anterior, foi

Tabela 4. Resumo de ANAVA e médias para fitomassa total (FT) e relação raiz/parte aérea $(\mathrm{R} / \mathrm{PA})$ de mudas de coqueiro aos 120 dias após plantio no viveiro, em função dos tratamentos (CEa) a que foram submetidas as plântulas durante a fase de germinação

\begin{tabular}{lcc}
\hline \multirow{2}{*}{ Fonte de variação } & FT & R/PA \\
\cline { 2 - 3 } & \multicolumn{2}{c}{ Quadrado Médio } \\
\hline Salinidade & $669,69^{*}$ & $23,29^{\mathrm{ns}}$ \\
Regr. Pol. Linear & $2666,01^{* *}$ & $22,43^{\mathrm{ns}}$ \\
Desv. Reg. & $23,66^{\mathrm{ns}}$ & $35,37^{\mathrm{ns}}$ \\
Resíduo & 181,98 & 43,13 \\
$\mathrm{CV}(\%)$ & 33,25 & 33,85 \\
\hline \multirow{2}{*}{${\text { CEa }\left(\mathrm{dS} \mathrm{m}{ }^{-1}\right)}$} & $\mathrm{g}$ & Média \\
2,2 & $54,10(635,1)$ & 18,84 \\
5 & $50,64(457,1)$ & 16,68 \\
10 & $42,91(841,0)$ & 21,68 \\
15 & $32,30(941,9)$ & 17,71 \\
20 & $22,90(931,5)$ & 21,88 \\
\hline
\end{tabular}

Equação de Regressão: FT $\rightarrow \mathrm{y}=-1,782 \mathrm{x}+59,171\left(\mathrm{R}^{2}=0,99 * *\right) ;(* *)$ Significativo a 0,$01 ;(*)$ Significativo a 0,05 de probabilidade; ( $\left(^{\text {ns }}\right)$ Não significativo; Entre parênteses, o incremento percentual em relação ao final da fase de sementeira

Tabela 3. Resumo de ANAVA e médias para comprimento de mudas (CM) aos 30, 60, 90 e 120 dias após repicagem (DAR) e taxa de crescimento diário (TCD) em comprimento de mudas do coqueiro, na fase de viveiro, em função de diferentes níveis de salinidade da água de irrigação (CEa) a que foram submetidas as plântulas, durante a fase de germinação

\begin{tabular}{|c|c|c|c|c|c|}
\hline \multirow{2}{*}{ Fonte de Variação } & \multicolumn{3}{|c|}{ Comprimento de muda (CM) } & \multirow[b]{2}{*}{$120 \mathrm{DAR}$} & \multirow{2}{*}{$\begin{array}{c}\text { TCD } \\
0-120 \text { DAR }\end{array}$} \\
\hline & 30 & 60 & 90 & & \\
\hline Salinidade & $421,25 * *$ & $438,36^{* *}$ & $250,44 * *$ & $290,56^{* *}$ & $0,0025^{\mathrm{ns}}$ \\
\hline Desv. Regressão & $29,76^{\mathrm{ns}}$ & $73,60^{\mathrm{ns}}$ & $19,36^{\mathrm{ns}}$ & $25,28^{\mathrm{ns}}$ & $0,0015^{\mathrm{ns}}$ \\
\hline Resíduo & 41,34 & 27,16 & 14,03 & 18,32 & 0,0018 \\
\hline $\mathrm{CV}(\%)$ & 17,01 & 9,63 & 5,73 & 5,72 & 10,45 \\
\hline 2,2 & $50,81(34,8)$ & $66,56(30,9)$ & $75,97(14,1)$ & $84,87(11,7)$ & 0,39 \\
\hline 5 & $44,06(31,1)$ & $61,62(39,8)$ & $71,72(16,4)$ & $82,65(15,2)$ & 0,41 \\
\hline 10 & $36,31(56,5)$ & $50,69(39,6)$ & $60,37(19,1)$ & $71,60(18,6)$ & 0,40 \\
\hline 15 & $34,00(52,5)$ & $52,06(53,1)$ & $60,36(15,9)$ & $69,20(14,6)$ & 0,39 \\
\hline 20 & $23,00(112,9)$ & $39,58(72,1)$ & $58,45(47,7)$ & $65,53(12,1)$ & 0,45 \\
\hline
\end{tabular}

Equações de Regressão: CM aos 30 DAR: $y=-1,391 x+52,315\left(\mathrm{R}^{2}=0,96^{* *}\right)$

CM aos 60 DAR: $y=-1,383 x+68,540\left(\mathrm{R}^{2}=0,92 * *\right)$

CM aos 90 DAR: $\mathrm{y}=-0,994 \mathrm{x}+75,761\left(\mathrm{R}^{2}=0,83 * *\right)$

CM aos 120 DAR: $\mathrm{y}=-1,136 \mathrm{x}+86,634\left(\mathrm{R}^{2}=0,93 * *\right)$

(**) Significativo ( $\mathrm{p}<0,01)$; ${ }^{\mathrm{ns}}$ ) Não significativo; a Ao final da fase de sementeira (repicagem) as mudas tinham comprimento de 37,7, 33,6, 23,2, 22,3 e 10,8 cm, respectivamente para os tratamentos

$\mathrm{T}_{1}$ a $\mathrm{T}_{5}$; entre parênteses, o incremento percentual em relação ao final da fase anterior 
consideravelmente maior nos tratamentos mais salinos. Novamente se constata ter ocorrido aclimatação (hardening) das plantas, conforme já discutido anteriormente (Bray et al., 2000; Hasegawa et al., 2000).

Ao final da fase II (viveiro), diferentemente do observado na etapa de sementeira, já não havia diferença na relação R/PA entre os diversos tratamentos (Tabela 4). Enquanto, ao final da fase $\mathrm{I}$, a relação R/PA no tratamento $\mathrm{T}_{5}\left(20 \mathrm{dS} \mathrm{m}^{-1}\right)$ correspondia a $1,83 \%$, ao final do trabalho na fase de viveiro este percentual representava $21,88 \%$, valor bem próximo do observado nos outros tratamentos. Após cessarem os efeitos tóxicos da salinidade, o sistema radicular das mudas de coqueiro se desenvolveu rapidamente, alcançando valores similares em relação à parte aérea, comparativamente aos observados no controle $\left(\mathrm{T}_{1}\right)$. Tal comportamento tem explicação nas características biológicas de emissão de raízes do coqueiro, em ordens sucessivas, decorrente da semente rica em substâncias de reserva e de sua mobilização ao longo de vários meses (FAO, 1984).

\section{Sistema de produção de mudas com águas salinas}

Pelos resultados do presente estudo, constata-se ser viável a produção de mudas de coqueiro Anão, em áreas sem disponibilidade de águas de baixa salinidade, situação comum em propriedades agrícolas localizadas no semi-árido nordestino (Audry \& Suassuna, 1995). Nessas áreas, a produção de mudas poderia ser iniciada 90 a 120 dias antes do período das chuvas, com base em série histórica de precipitação pluvial, utilizando águas salinas de até $20 \mathrm{dS} \mathrm{m}^{-1}$, provenientes de poços ou de dessalinizadores; com a chegada do período chuvoso, far-seia repicagem para sacos plásticos em viveiro. Além de representar uma fonte extra de renda para o agricultor, essa atividade abriria perspectivas de absorção de mão-de-obra não especializada, justamente na época de menor atividade agrícola na região, contribuindo para diminuir o êxodo rural.

\section{CONCLUSÕES}

1. A salinidade de até $20 \mathrm{dS} \mathrm{m}^{-1}$ não afeta a germinação do coqueiro cv Anão Verde, mas retarda a emissão do broto germinativo em 11 dias, em relação ao uso de água com 2,2 $\mathrm{dS} \mathrm{m}{ }^{-1}$.

2. O sistema radicular é a parte da planta mais afetada pela salinidade, na fase de sementeira.

3. Na fase de plântula, o estresse salino começa a afetar a fitomassa total a partir de $5,06 \mathrm{dS} \mathrm{m}^{-1}$.

4. As plântulas oriundas de germinação sob condições de alta salinidade, após passarem a ser irrigadas com água de 2,2 $\mathrm{dS} \mathrm{m}^{-1}$, se recuperam e passam a crescer no mesmo ritmo daquelas germinadas sem estresse salino.

\section{LITERATURA CITADA}

Aldesuquy, H.S.; Ibrahim, A.H. Water relations, abscisic acid and yield of wheat plants in relation to the interactive effect of seawater and growth bioregulators. Journal of Agronomy and Crop Science, Braunschweig, v.187, n.1, p.97-104, 2001.
Alian, A.; Altman, A.; Heuer, B. Genotypic difference in salinity and water stress tolerance of fresh market tomato cultivars. Plant Science, Columbus, v.152, n.1, p.59-65, 2000.

Alshammary, S.F.; Qian, Y.L.; Wallner, S.J. Growth response of four turfgrass species to salinity. Agricultural Water Management, Amsterdam, v.6, n.1, p.97-111, 2004.

Amorim, J.R.A.; Fernandes, P.D.; Gheyi, H.R.; Azevedo, N.C. Efeito da salinidade e modo de aplicação da água de irrigação no crescimento e produção de alho. Pesquisa Agropecuária Brasileira, Brasília, v.37, n.2, p.167-176, 2002.

Audry, P.; Suassuna, J.A. A qualidade da água na irrigação do trópico semi-árido - um estudo de caso. In: Seminário Franco-Brasileiro de Pequena Irrigação, 1990. Recife, Anais... Recife: CNPq, SUDENE, 1995, p.147-153.

Bie, Z.; Ito, T.; Shinoara, Y. Effects of sodium sulfate and sodium bicarbonate on the growth, gas exchange and mineral composition of lettuce. Scientia Horticulturae, Amsterdam, v.99, n.2, p.215-224, 2004.

Braga, J.M. Avaliação da fertilidade do solo. Viçosa: Universidade Federal de Viçosa, 1983. 82p, Ensaios de campo.

Bray, E.A.; Bailey-Serres, J.; Weretilnyk, E. Responses to abiotic stresses. In: Buchanan, B.; Jones, R. (eds.) Biochemistry and molecular biology of plants. Rockville: American Society of Plant Physiologists, 2000. p.1158-1203.

Cuenca, M.A.G. Importância econômica do coqueiro. In: Ferreira, J.M.S; Warwick, D.R.N; Siqueira, L.A. A cultura do coqueiro no Brasil. Brasília: Embrapa-SPU; Aracaju: EMBRAPA-CPATC, 1998. cap.2, p.65-71.

FAO. Coconut, tree of life. Plant production and protection. Rome: FAO, Paper 57, 1984. 446p.

Ferreira Neto, M. Desenvolvimento e produção do coqueiro sob diferentes salinidades de água de irrigação. Campina Grande: UFPB, 2001, 88p. Dissertação Mestrado

Ferreira, P.V. Estatística experimental aplicada à agronomia. Maceió: UFAL/ EDUFAL/FUNDEPES, 2000. 437p.

Fontes, H.R.; Cintra, F.L.D.; Carvalho Filho, O.M. de. Implantação e manejo da cultura do coqueiro. In: Ferreira, J.M.S; Warwick, D.R.N; Siqueira, L.A. A cultura do coqueiro no Brasil. Aracaju: Embrapa-CPATC, 1998. p.99-71

Fontes, H. R.; Leal, M. de S. Efeito da irrigação, cobertura morta e entalhe da semente, sobre a germinação de coqueiro 'Gigante-do-Brasil'. Aracajú: EMBRAPA-CNPCo, 1994. 7p. Comunicado Técnico, 5

Ghoulam, C.; Fares, K. Effect of salinity on seed germination and early seedling growth of sugar beet. Seed Science and Technology, Zurich, v.29, n.2, p.357-364, 2001.

Gurgel, M.T.; Fernandes, P.D.; Gheyi, H.R.; Santos, F.J.S.; Nobre, R.G. Índices fisiológicos e de crescimento de um porta-enxerto de aceroleira sob estresse salino. Revista Brasileira de Engenharia Agrícola e Ambiental, Campina Grande, v.7, n.3, p.451-456, 2003.

Hasegawa, P.M.; Bessan, R.A.; Zhu, J.K.; Bohnert, H.J. Plant cellular and molecular responses to high salinity. Annual Review of Plant Physiology, Plant Molecular and Biology, Palo Alto, v.51, n.3, p.463-499, 2000.

IBGE - Instituto Brasileiro de Geografia e Estatística. Anuário Estatístico do Brasil. Rio de Janeiro, v.60. 2000, p.3-27, 347. 
Katerji, N.; Van Hoorn, J.W.; Hamdy, A.; Mastrorilli, M. Salinity effect on crop development and yield analysis of salt tolerance according to several classification methods. Agricultural Water Management, Amsterdam, v.62, n.1, p.3766, 2003.

Manchanda, H.R.; Bhandhari, D.K. Effect of presoaking of seeds in salt solutions on yield of wheat and barley irrigated with highly saline waters. Journal Indian Society of Soil Science, New Delhi, v.24, n.3, p.432-435, 1976.

Marinho, F.J.L.; Fernandes, P.D.; Gheyi, H.R. Desenvolvimento inicial do abacaxizeiro cv, Smooth Cayenne, sob diferentes condições de salinidade da água. Revista Brasileira de Engenharia Agrícola e Ambiental, Campina Grande, v.2, n.1, p.1-5, 1998 .

Munns, R. Comparative physiology of salt and water stress. Plant Cell and Environment, Logan, v.25, n.2, p.239-250, 2002.

Noaman, M.N.; El-Haddad, E.S. Effects of irrigation water salinity and leaching fraction on the growth of six halophyte species. Journal of Agricultural Science, New York, v.135, n.3, p.279-285, 2000.

Pomier, M.; Brunin, C. Irrigation des cocotiers à I'eau salée. Oléagineux, Paris, v.29, n.1, p.183-186, 1974.
Rodrigues, L.N.; Fernandes, P.D.; Gheyi, H.R.; Viana, S.B. Germinação e formação de mudas de arroz irrigado sob estresse salino. Revista Brasileira de Engenharia Agrícola e Ambiental, Campina Grande, v.6, n.2, p.397-403, 2002.

Silva Jr., C.D.; Passos, E.E.M.; Gheyi, H.R. Aplicação de água salina no desenvolvimento e comportamento fisiológico do coqueiro. Revista Brasileira de Engenharia Agrícola e Ambiental, Campina Grande, v.6, n.1, p.39-44, 2002.

Tester, M.; Davenport, R. $\mathrm{Na}^{+}$tolerance and $\mathrm{Na}^{+}$transport in higher plants. Annals of Botany, London, v.91, n.3, p.503527, 2003.

Viana, S.B.A.; Fernandes, P.D.; Gheyi, H.R.; Soares, F.A.; Carneiro, P.T. Índices morfofisiológicos e de produção de alface sob estresse salino. Revista Brasileira de Engenharia Agrícola e Ambiental, Campina Grande, v.8, n.1, p.23-30, 2004.

Yusuf, M; Varadan, K.M. Water management studies on coconut in India. In: Nair, M. K.; Klan, H.H.; Gopalasundaram, P.; Bhaskaararao, E. V. V. Advances in Coconut Research and Development. New Delhi: IBH, 1993. p.337-346.

Zeng, L.; Shannon, M.C.; Lesch, S.M. Timing of salinity stress affects rice growth and yield components. Agricultural Water Management, Amsterdam, v.48, n.1, p.191-206, 2001 